The only surprise is the great difference between the critical temperatures for ethylene bromide and carbon disulfide mixtures. Until a more quantitative treatment is given we will not attempt to account for this difference.

\title{
Summary.
}

Critical temperatures of mixing of liquid phosphorus withother substances have been determined as follows, decane, > 300; chlorobenzene, 264; naphthalene, 202; phenanthrene, 200; $p$-dibromobenzene, I63; carbon disulfide, -6.5 . These figures confirm predictions made in a previous paper.

BERKELEY, CALIT.

[CONTRIBUTION FROM THE DEPARTMENT OF CHEMISTRY, PRINCETON UNIVERSTTY.]

\section{A METHOD OF MEASURING LOW VAPOR PRESSURES, WITH ITS APPLICATION TO THE CASE OF TRINITRO-TOLUENE.}

\author{
BY AI,AN W. C. MENZTES. \\ Received September 7, 1920 .
}

The method most in favor for the measurement of rather low vapor pressures is perhaps the gas-current saturation method. Against this method may be urged its cumbrousness; the trouble of maintaining constant temperatures far from room temperature over prolonged periods of time; the need of the assumption of a normal molecular weight for the vapor in question; and other objections, ${ }^{1}$ varying in seriousness with circumstances. It is, therefore, perhaps of interest to note that a single McLeod gage can be very simply utilized in measuring low vapor presstures, yielding readings for different temperatures as fast as a bath can be adjusted to each new temperature. The present paper indicates how such measurements may be carried out.

Outline of the Method.-Elsewhere, ${ }^{2}$ the writer has described a method for measuring vapor pressures involving the use of 2 McLeod gages, one of which actually contained the vapor in question. In the present case, in which one gage only is used, none of the vapor enters the gage.

The apparatus consists of a McLeod gage, immersed in a large vessel of stirred water to secure constancy of temperature, and connected by capillary glass tubing with a bulb, preferably cylindrical, which can be completely submerged in a bath or surrounded by a jacket to give it the temperatures desired. The bulb, which may be of glass, porcelain, platinum or other material, should have as large a volume as convenient relative to that of the gage. 'This simple system is connected through a mercury seal to a source of dry inert gas and to a vacuum pump. The system.

${ }^{1}$ Cf. Menzies, This Journar, 42, 978 (1920).

Ibid., 4I, 7783 (1919). 
may thus be charged with, for example, dry nitrogen ${ }^{1}$ at any pressure desired. If now the temperature of the bulb be raised, the gage should indicate an increased pressure close to that which may be computed by the gas laws from the known temperatures and previously ascertained volumes of the hot and cold parts of the system. Initial and final bulb temperatures may obviously be chosen to suit the case. For vapor-pressure measurement, in addition to the inert gas, the bulb is charged with suffcieat of the substance under examination to furnish more than enough of its attenuated saturated vapor to fill the bulb completely. Vapor may be prevented from reaching the gage by sufficiently cooling a portion of the connecting tube. The initial temperature of the bulb is chosen conveniently so low that the vapor pressure of the substance will be small or negligible compared with its vapor pressure at the final temperature. Thus, when the apparatus is operated as before, one obtains a higher final pressure than if nitrogen only were present, and, from this pressure excess, an obvious application of the gas laws enables one to compute the vapor pressure of the substance at the final temperature, provided in particular, that Dalton's law may be assumed.

It would appear that the only investigator who has, in a particular case, made use of a form of this simple method of vapor pressure measurement is Villiers. 2

The Case of T. N. T.-Knowledge of the vapor pressures of T. N. T. in a short range above its melting-point was desired by the Division of Chemistry and Chemical Technology of the National Research Council, and the case was studied as a War Problem at their request. The sample was furnished through Dr. Comey and was stated to have a meltingpoint of $80.5^{\circ}$, in agreement with Comey's published work on this meltingpoint. ${ }^{3}$ Any attempt at purification other than desiccation ${ }^{4}$ in absence of light was purposely omitted for obvious reasons. 'The sample is correctly nomed merely "T. N. T.," not "alpha trinitrotoluene."

Details and Discussion of Procedure and Measurements.-The McLeod gage, together with the cold connecting tubes, had a corrected volume of $10.69 \mathrm{cc}$, and the bulb a corrected volume of $94.0 \mathrm{cc}$. The dry nitrogen which was used as the inert gas was given a pressure of 0.5852 mm. of mercury at $23.0^{\circ}$. So far as the determination of the pressure difference with and without vapor is concerned, the greatest sensitiveness would be obtained by using a nitrogen pressure only slightly greater than the highest vapor pressure to be measured; on the other hand, divergence

1 Cf. Menzies, This Journal, 4r, I784 (1919).

${ }^{2}$ Villiers, Ann. chim. phys, [8] 30, 588 (1913).

${ }^{3}$ Comey, J. Ind. Eng. Chem., 2, I03 (1910). See also Carlton Smith, "T. N. T. and Other Nitrotoluenes," rgr8, p. 75; Bell and Herty, J. Ind. Eng. Chem., x т, iा 24 (Igrg), where this $\mathrm{m}$. p. is discussed with literature references.

4 Cf. Huff, Chem. Met. Eng., 21, 570 (1919). 
from Dalton's law is more to be feared with such relatively low pressures of permanent gas. Possible error due to the solution of nitrogen in the molten T. N. T. was minimized by the fact that only a minute quantity, less than a Ing., was necessary in the bulb to insure saturation. By employing different nitrogen pressures, this exror, had it been serious, could have been completely eliminated, as also could error arising from departure from Dalton's law. Very slow condensation of $T$. N. T. took place in the capillary tube where it emerged from the heating bath, and care was taken to note that the T. N. T. at the bottom of the bulb did not become exhausted. The heating bath and the thermometry were similar to those formerly described. ${ }^{1}$ Readings were taken with the gage at $23.0^{\circ}$ in all cases, and with the buib at $23.0^{\circ}, 81.6^{\circ}, 90.1^{\circ}$, and $102.6^{\circ}$, giving vapor pressures of $0.046,0.067$ and $0.120 \mathrm{~mm}$. of mercury at $0^{\circ}$, respectively, for the last 3 temperatures. Correction for thermal expansion of the bulb could be neglected. The observations were completed within 2 hours.

The logarithms of these pressures were plotted against the reciprocals of the corresponding absolute temperatures, and pressures for each whole degree were read off from the straight line that passed very closely through the 3 datum points. These values are given in Table $I$.

TABLE I.

$\begin{array}{cccc}\begin{array}{c}\text { Vapor Pressures of Liquid T. N. T. in Mm. of Mercury at } 0^{\circ} . \\ \text { Temperature. }\end{array} & \begin{array}{c}\text { Pressure. } \\ \text { MIm. }\end{array} & \begin{array}{c}\text { Temperature. } \\ \text { Pressure. }\end{array} & \begin{array}{c}\text { C. } \\ \text { Mm. }\end{array} \\ (80) & (0.042) & 92 & 0.074 \\ (81) & (0.044) & 93 & 0.078 \\ 82 & 0.046 & 94 & 0.081 \\ 83 & 0.048 & 95 & 0.085 \\ 84 & 0.05 \mathrm{r} & 96 & 0.089 \\ 85 & 0.053 & 97 & 0.093 \\ 86 & 0.056 & 98 & 0.098 \\ 87 & 0.059 & 99 & 0.102 \\ 88 & 0.062 & 100 & 0.106 \\ 89 & 0.064 & 101 & 0.110 \\ 90 & 0.067 & 102 & 0.116 \\ 91 & 0.070 & & \end{array}$

Confirmation by Gas Current Saturation Method.-As one could not, a priori, be certain that the gas laws were followed strictly by the mixture of gas and vapor in the bulb, confirmation of these values was sought by a measurement by the gas current saturation method. For this purpose, the T.N.T. was melted over the surface of several $g$. of glass wool which had previously been washed with nitric acid, steamed and dried. The very large surface of T. N. T. thus produced was contained within a wei ghed saturator tube which could be maintained at the boilingpoint of water. The loss of weight of this tube gave the weight of vapor

1 Menzies, Thts Journal, 4I, 178,3 (1919). 
concerned. The volume of the air current used was measured, not by use of an aspirator as is customary, but by weighing the water it evaporated at $25^{\circ}$ from a water saturating train described in another place, ${ }^{1}$ where also necessary precautions and corrections are referred to. Preliminary experiments having shown that an air speed of half a liter per hour gave saturation, the experiment was continued for 5 days in order to obtain a satisfactorily large loss of weight $(5 \mathrm{mg}$.) from the saturator. On account of fluctuation in the barometric pressure over this period, the suitably weighted mean of many observations of the actual temperature of the saturator tube was employed. This was $99.5^{\circ}$, while the found vapor pressure was $0.102 \mathrm{~mm}$. The vapor pressure for $99.5^{\circ}$ as read from the curve given by the previous observations is 0 . I04, thus showing a degree of concordance rather closer than could be anticipated.

Either the assumptions involved in the application of each of the 2 methods are justified in this instance, or else the error is fortuitously the same for both in direction and amount. Further comment is reserved for a later publication.

\section{Summary.}

A method has been outlined by which low vapor pressures may be measured by the help of a single McLeod gage. This method is much more expeditious than the gas-current saturation method but, like it, is of accuracy subject to the truth of certain assumptions. Its application, with certain precautions necessary to its use, has been illustrated in the case of $T . N . T .$, whose vapor pressures are here reported for each degree from $82^{\circ}$ to $102^{\circ}$.

Pritacaron, N. J.

[CONTRIBUTION FROM THE WOLCOTT GibBs Memorial Laboratory OF Harvard UNIVERSITX.]

\section{A REVISION OF THE ATOMIC WEIGHT OF ALUMINUM. THE ANALYSIS OF ALUMINUM BROMIDE. PRELIMINARY PAPER.}

By ThEODORE W. RichaRdS AND HERRY KREFELRA. Received September 27, 1920.

The usually accepted atomic weight of aluminum (27.I) is based chiefly on the work of J. W. Mallet, ${ }^{2}$ published in $\mathrm{r} 880$. The earlier researches of Davy, Thomson, Berzelius, Mather, Dumas, Tissier, and Terreil regarding this subject were considered carefully in Mallet's paper and therefore need not be detailed here. Those of Isnard and Baubigny are sufficiently described by Clarke, ${ }^{3}$ who gives the bibliographical references to

i Menzies, ThIs Journal, 42, 978 and 1953 ( 1920 ).

'Mallet, Phil. Trans., I7I, 1003 (I880).

"F. W. Clarke, "Recalculation of Atomic Weights," Smithsonian Inst. Pub., 54, No. 3. 262 (1910). 